\title{
Chemistry and the State. ${ }^{1}$
}

\section{By Sir Robert Robertson, K.B.E., F.R.S.}

$\mathrm{T}^{\mathrm{H}}$ HE appeal of the State to chemistry has developed through the gradual recognition of the need for the application of that science to matters relating to its preservation, its currency, its financial support, its health, its food supply, its industries, and finally to academic science. In the course of this development in Great Britain, advantage has been taken, if sometimes tardily, of the general advance in chemical knowledge, and frequent recourse has been had to the advice of well-known chemists of the day, and collectively of the Royal Society; thus for various purposes the following chemists, as officials or consultants, have in the past afforded assistance in the solution of specific problems referred to them, or by taking part in Commissions : Boyle, Newton, Davy, Faraday, Daniell, Graham, Hofmann, Redwood, Abel, Roberts-Austen, Percy, Dupré, Playfair, Frankland, Ramsay, and Dewar. It has happened in several instances that as a result of these Commissions and references to chemists, some definite chemical activity of the State has emerged.

The following summary reviews the State's chemical activities before, during, and after the War.

\section{BEFORE THE WAR.}

Defence.-For the defence of the State, establishments for the production of explosives were early maintained, and when this ultimately took the form of a chemical manufacture, the Government factory took the lead in devising efficient processes, while from the various State research establishments has issued during the last fifty years an important body of original contributions to the theory of explosives and to the knowledge of their properties.

Metallurgy.-The metallurgical progress of the country has always been a concern of the State by reason of its application to defence by land and sea, and close touch has been maintained with successive developments in the manufacture and use of cast iron, wrought iron, steel, and non-ferrous alloys. While the main advances in process have been made in the great iron and steel works, material contributions to knowledge in this sphere have been made by chemists in the Government service.

Revenue.-For the revenue of the State, imposts were applied in early times, but with great uncertainty, until the charge was put on a scientific basis. Very accurate tables for the strength of alcohol were worked out under the supervision of the Royal Society at the end of the eighteenth century, to be superseded by revised ones issued only a few years ago, when, in addition, new tables were issued also by the Government Laboratory, for determining the gravity of worts before fermentation. The question of rendering alcohol unpotable, but still useful for industrial purposes, has occupied much attention. It was on account of the necessity for safeguarding the revenue that the Government Laboratory was primarily erected, although it now performs chemical work for all State Departments of Great Britain.

I From the presidential address to Section B (Chemistry) of the British Association, delivered at Toronto on August 7.
Health.-The three main steps with regard to public health and sanitation in this period were the forcing of these questions into prominence by Playfair, with the consequent Commissions and legislation leading to the formation of the Local Government Board and its successor, the Ministry of Health, which has many varied activities in preserving purity of air and water and protecting the workman in dangerous trades; secondly, the determination of standards for a safe water supply by the pioneering work of Frankland; and, thirdly, the appointment of public analysts by the local authorities, with the Government Laboratory as referee, for safeguarding the supply of food.

Agriculture.-Science was being applied to agri. culture about the end of the eighteenth century, and at the beginning of the next, Davy did pioneering chemical work for the Board of Agriculture. Private endeavour is responsible for the next development, State action being limited to the prevention of fraud in the sale of fertilisers and feeding-stuffs. In Igog, however, the annual allocation of a sum of money to the Development Commission for the advancement of agriculture stimulated research in a large number of institutions engaged in the scientific study of problems in which chemistry plays an important part.

Other Activities. - In addition to the chemical work referred to above, there is a variety of subjects connected with State Departments to which chemists have contributed, such as the composition of the sea, and the composition and physical chemistry of rocks and building-stone. At the Government Laboratory a large number of investigations have been conducted on matters directly referred from Government Departments.

\section{DURING THE WAR.}

In all the activities described, the War requisitioned the work of the chemist, but, naturally, predominantly to meet the demands of active warfare.

Defence.-The attention that had been bestowed on the subject of propellants enabled expansion to take place with no important alteration in the technique of their manufacture, to which was adapted a new type. of cordite, ultimately made on the largest scale, without using an imported solvent. For high explosives Great Britain was in much worse case, as these had not been made by Government, and were manufactured only in small quantity. Their study at Woolwich led to a rapid evolution of new processes, substances, and methods of use. Thus a method was worked out for the manufacture of trinitrotoluene, and to save this substance a new high explosive, amatol, was devised. This explosive, consisting of ammonium nitrate and trinitrotoluene, passed exhaustive trials and was ultimately produced at the rate of 4000 tons a week. The production of the ammonium nitrate for the mixture was in itself a stupendous undertaking, and the methods of filling the explosive into shell and other munitions gave rise to much ingenuity. In the Research Department, Woolwich, the number of qualified chemists engaged NO. 2863 , VOL. I I 4 ] 
in the study of explosives in all their aspects ultimately exceeded a hundred, while for manufacture and inspection more than a thousand were employed. The ideal set before himself by Lord Moulton in I9I4, to produce nothing less than the maximum of explosives of which Great Britain was capable, was realised, and they assumed a quality and character that caused them to be copied by our Allies, and proved themselves more trustworthy than those of the enemy.

Starting unprepared, and without the advantage of a well-developed fine chemical industry, Great Britain was able ultimately to make a reply in the field of chemical warfare that was rapidly becoming more and more effective; at the same time, by study and often self-sacrificing experiment, protecting the soldier by the development of very efficient respirators. In this connexion and in that of explosives, nearly every professor of chemistry in the country, and many from beyond the sea, were engaged.

Metallurgy.-The enormous demand for metals for munitions and countless other war requirements led to an unprecedented concentration of the metallurgical industries on the needs of the State, and to an equal concentration of metallurgical science on investigation devoted to improvement in quality of materials for new and special war purposes. The work of the Aircraft Production Department, aided by many metallurgists and engineers, on alloy steels; of the National Physical Laboratory on aluminium alloys; and of the Metallurgical Branch of the Research Department, Woolwich, on the heat-treatment of heavy forgings and on the drawing of brass, is typical of the successful effort made in every quarter. The knowledge thus gained was disseminated in the form of specifications, instructions, and reports, and has had a great and permanent effect on manufacture.

Health.-A committee of the Royal Society had been studying food values, and was able to afford the Food Controller, when he took office, valuable data bearing on the rationing of food. The committee had dealt with subjects which shortly became of much importance, such as a better recovery of flour in milling wheat. The chemical examination of the food for the Army during the War, carried out by the Government Laboratory, employed a large staff of chemists. For the supply of many fine chemical substitutes used in medicine and surgery, formerly imported from abroad, such provisional arrangements had to be made as the organisation of a large number of university laboratories on a semi-manufacturing basis.

Agriculture.-Effects on agriculture during the War were shortage of the usual feeding-stuffs for cattle and of fertilisers. The chemists stationed at Rothamsted gave special attention to the shortage of manures and prepared instructions for the guidance of farmers; and several sources of supply of potash were exploited, including kelp, felspar, and the flue-dust of furnaces. As sulphuric acid was required for explosive work, fine grinding of phosphates and basic slag was adopted and found to be more efficient than was expected. Shortage also directed the attention of chemists to the use of little known food-stuffs, especially for cattle, and the information gained as to their feeding value was important.

No. 2863 , VOL. I I 4 ]
Other Activities.-In many other activities in connexion with the War, chemists were directly involved, such as in affording advice on the conservation of materials, on the numerous questions arising from the operations of the War Trade Department, on the restriction of imports and exports, and on matters of contraband.

\section{AfTER THE WAR.}

The magnitude of the chemical effort, it can be claimed, was a factor in winning the War which must be reckoned as of importance only second to that of the bravery of our forces in the field. But it has left a lasting mark, and given to chemistry a value which, were it not for the rapidity with which the achievements of science are forgotten, ought to keep before the public its connexion with almost every phase of activity.

Defence.--To take our subjects in the same order, we may consider some of the effects of the energy spent on the production of munitions. The intensive study of explosives and of other chemical substances used in the War has led to a more complete knowledge of their chemistry, their physical and explosive properties, and has advanced chemical theory. These advantages are not of military importance only, but are reflected also in the production of trade explosives. The collected records of the Department of Explosives Supply afford examples of treatment of many problems of interest to the general chemical technologist, and not only to the explosives expert.

A further benefit was reaped by chemists in every position, from the professor to the youngest graduate, coming into direct contact with manufacturing methods and thus gaining insight into the applications of their science. While it is true that the opportunity came to few of these to take part in the design of plant and primary choice of process, nevertheless the experience was a novel one, as it led them into the field of technology, and cannot fail to have widened their outlook. It became apparent that there was a shortage of a type of chemist which had been developed in Germany, skilled in the transference of the chemical process from the laboratory to the works scale in the largest enterprises. A chemist of this type is one who, besides having a sound knowledge of chemistry and physics, has had experience in the materials of construction used on the large scale, and in the operation of the usual types of plant for carrying out the operations of chemical manufacture, and is capable of working out flow-sheets illustrating the process, and operating plant with every regard to economy. The need for instruction in such subjects had been borne in on men like the late Lord Moulton, and as a direct result of the war-time experience of our deficiencies in this direction has arisen the movement for creating chairs of chemical engineering in some of our universities. It is to be expected that from these schools, especially where the instruction is superimposed upon a full graduate course, will come men who will lead the way in the application of academic science to industry.

Metallurgy.-While the interest of metallurgical science in war material has fortunately fallen to a peace-time level, State participation in the support of scientific research remains far greater than before the 
War. In metallurgy it is exercised through the Department of Scientific and Industrial Research, with its organisations of the National Physical Laboratory and the Industrial Research Associations, as, for example, those dealing with the non-ferrous metals and with cast-iron. The State also continues to maintain efficient research departments for the Fighting Services, but it is significant that the largest of these is undertaking industrial metallurgical research on a considerable scale, for the benefit of the brass and other industries. State support and encouragement are undoubtedly powerful factors in the rapid progress now taking place in every branch of metallurgical science in Great Britain, and there is scarcely any related industry which can fail to benefit.

Revenue.-Since the War the principal matters affecting the revenue are the higher duties, which have rendered necessary a further denaturation of alcohol. Improved facilities have been granted for the use of alcohol for scientific purposes and in industry ; regulations have been formulated for the use of power alcohol, and duties have been established on imported fine chemicals and synthetic dyestuffs.

Health.-The food shortage during the War directed attention to the nature and quantity of our food supplies, and led to further investigations being undertaken by the Department of Scientific and Industrial Research on food preservation and storage. Activity is also shown by the appointment of committees which are working on the subject of preservatives and colouring matter in food, and on the pollution of rivers by sewage and trade effluents. A great field is open in the co-operation of chemistry with medicine in the discovery of substances suitable for the treatment of the numerous diseases now traced to parasites in the blood.

Agriculture.-So far as fertilisers are concerned, the lack of a supply of fixed nitrogen from the air which obtained throughout the War has now been rectified, and Great Britain for the first time is no longer exceptional among the nations by neglecting to provide itself with synthetic ammonia for agriculture and for munitions. Such war-time expedients as the use of nitre-cake instead of sulphuric acid for making ammonium sulphate and superphosphate, and the recovery of potash from flue-dust, have not survived, but there has been a gain in the further development of "synthetic farmyard manure" and the increased use of basic slag. The present activity in research in agricultural chemistry of a fundamental character is leading to a better understanding of problems of the soil and of plant and animal nutrition, and cannot fail to be of ultimate benefit to farming.

Organised Applied Research and Assisted General Research.-Established during the War as a result of an appreciation of the contrast between the successful application of scientific method to military purposes and the want of such application to many of our manufactures, the Department of Scientific and Industrial Research has extended over a wide field. Its main activities are in the directions of State encouragement to industry to apply chemistry to its problems, of State investigation of vital problems beyond the sphere of private enterprise, and of assistance to workers in the purely academic field. In all these spheres activity is shown by the contributions to knowledge already forthcoming.

\section{PERSONNEL.}

In the expansion that has occurred in the chemical sections of State Departments since the War, it is interesting to note the increase in the number of chemists that are employed. So far as can be gathered, the number of chemists working in departments maintained wholly by the State is 375 for the present year, compared with $\mathrm{I}_{50}$ in $\mathrm{I}_{912}$, while in establishments to which the State affords partial support, such as those under the Development Commission and the Research Associations, the corresponding numbers are 150 and 50. In addition, grants are made to $\mathrm{I} 45$ research students and to II independent research workers, involving a yearly sum of about $50,000 \mathrm{l}$.

\section{Development of Chemistry in the Modern State.}

From the foregoing account of the connexion of the Departments of State in the United Kingdom with chemistry, it is possible to trace a gradual development and ultimately a change in attitude, in passing through the stages of compulsion, expediency, and assistance.

From motives of security the State was compelled to give heed to chemical matters involved in its defence, such as those which appertained to munitions of war, including metals used in their manufacture; it was constrained to uphold the standard of its currency; and it was obliged to secure a revenue. As a consequence, the first chemical departments were set up in connexion with these activities, and from them have emanated notable additions to chemical knowledge, improvements in methods of manufacture, and specifications for Government requirements that have led to improved material becoming available for civilian use. Although mostly conducted with inadequate staff, the study of these questions, it can be claimed, proved of national advantage when the time of need arose.

In the next stage, the public conscience having been awakened by the pioneering work of Playfair, it appeared expedient to safeguard health by attention to sanitation, and, as the quality of food was unsatisfactory, to set up a chemical control. Although a start was made by Davy, a member of the Board of Agriculture of the day, progress in this subject passed to private enterprise, and a century elapsed before direct assistance was afforded to this important matter. Out of these activities come our present system of supervision over the purity of air, water and food, and also the recent progress made in the application of chemistry and physics to problems of the soil.

The last and more recent stage is in the nature of a recognition that the State is under an obligation to assist science, and in this case the science of chemistry, on which so many important industries are based. The War brought home the danger that, although the record of Great Britain as regards discovery in pure science was unrivalled, its systematic application was too often left to other countries, with the result of lamentable shortages during the War and the risk of many industries being ineffective in peace. A measure of government intervention and action appeared

NO. 286.3, VOL. I I 4 ] 
requisite, and research became the business of a government department. Outside of the great firms which maintain progressive chemical staffs, the firms in numerous industries have been encouraged and assisted to co-operate in the betterment of their manufactures by the application of the methods of science, and from these associations and the organisations dealing with national problems begins to flow a stream of communications indicative of useful work accomplished. Nor is the foundation of it all neglected, for encouragement is given to workers in the academic field to follow out their ideas, whithersoever they may lead them, in accordance with the truth that " research in applied science might lead to reforms, but research in pure science leads to revolutions."

It is important to be able to record an advance in securing an interchange of information among government departments, and between their work and that of the universities, a matter which before the War was unsatisfactory, as it was mainly personal and sporadic. It is also a hopeful sign that, although the knowledge and appreciation of the methods and capabilities of science are still generally wanting, there have been signs of late years that these matters are coming to engage the attention of those who guide the policy of the State.

\section{Centenary of the Franklin Institute.}

$\mathrm{O}$ $\mathrm{N}$ March $30, \mathrm{x} 824$, the Governor of the State of Pennsylvania signed an Act incorporating the Franklin Institute for the Promotion of the Mechanic Arts. The centenary of its foundation will be observed in Philadelphia on September $17, \mathbf{r} 8$, and 19 , by celebrations reminiscent of the rise, growth, and continuity of purpose of a remarkable institution, now, after many inevitable vicissitudes, rooted deeply in the national life of the United States, at the same time commanding the allegiance of men of science in most other countries. Accordingly, delegates representing several of the universities of Great Britain, as well as scientific societies, will join those from Canada, France, Holland, and Germany in united expression of congratulation. To have wrested "secrets of excellent use" from Nature marks and cements the common bond.

When we direct our minds back to the Institute's initial year, 1824 , it serves us to recall that here, in England, we had Sir Humphry Davy - at the height of his fame-installed as president of the Royal Society, whilst round about that period many special scientific organisations were springing into being. Among such were the Horticultural Society (I804), Geological Society (I807), Institution of Civil Engineers (1818), the Royal Geographical Society (I830) and the British Association (I83I).

The Franklin Institute was established to meet the need for an institution similar to that founded in London in I799 (the Royal Institution) by Benjamin Thompson, Count Rumford. The founders had before them, also, the history and objects of the Anderson College of Glasgow, where Dr. George Birkbeck had lectured on mechanics and applied science with inspiring zeal and successful issue. The initial tentative effort was due to two Philadelphians, Samuel V. Merrick and William H. Keating, the latter then chosen by the University of Pennsylvania to occupy a new Chair of Chemistry in its Application to Agriculture and the Mechanic Arts. They discussed a projectone of them, by the way, had been told he was wasting his time-but they were bent upon going forward. They called in two others as colleagues, and the four -all young men-using the Philadelphia Directory, selected from it the names of some I 500 citizens, inviting them by circular letter to attend a meeting on the evening of February 5, I824, to discover and talk over plans. The meeting was a success, not a little to the surprise of its conveners, approbation of the purpose in view, namely, that of assisting the knowledge of physical science and its diffusion in the arts and sciences, being expressed freely. Later, an election of officers took place, and the promoters chose a name for their offspring. Certainly none could have been more fitting than that of "Franklin Institute," both for immediate testimony and posterity's keeping. There seems to have been no dissension. The glamour of the great "printer-philosopher" was with them in the city where he had worked, and hence homage was rendered. The original scheme prospering, in twelve months' time the corner-stone of a marble-fronted building, destined as a home, was laid (we are told " in ancient and Masonic form by the Grand Lodge of Philadelphia, in the presence of the Society") on June 8, 1825 , and completed in 1826 . Upon the first floor (to-day) are located the lecture room, laboratories, and offices. The second floor is occupied by the library, whilst the third is devoted to the Museum of Models and Historical Apparatus.

Membership of the Institute is open to men and women, without regard to distinction of race, nationality, or religion, the only requirements for admission being good character and interest in its work. The artisan and the professor meet within its walls upon an equal footing, and it is to this happy blending of "Science with Practice" that the particular usefulness, past and present, of the Institute must be ascribed. General meetings are held once each month, except during the summer. At these, inventions and discoveries, important engineering projects and notable achievements in all fields of scientific progress, are presented, exhibited, or discussed. Many epochmaking inventions have been shown in their experimental stages at these meetings-for example, the phonograph, electric arc, the typewriter, liquid air apparatus, and telegraphy improvement devices. The average membership for the period I9I2-I922 was $\mathrm{r} 380$, and in view of the greater interest now manifested in the Institute's work, special efforts are to be made towards an enlargement of its roll.

Three permanent features of the Institute's activities are the maintenance of a reference library, the holding of exhibitions, and the publication of a Journal for the diffusion of knowledge on all subjects connected with science and the useful arts. All three formed part of the original plan of the founders, and the efflux of time has added materially to their importance. We gather from a recent report referring to the library that it is, 